\title{
Avaliação agronômica de linhagens de aveia-branca em duas regiões fisiográficas do Rio Grande do Sul ${ }^{1}$
}

\author{
Vilmar Tafernaberri Júnior ${ }^{2}$, Miguel Dall'Agnol ${ }^{3}$, Daniel Portella Montardo ${ }^{4}$, Emerson André \\ Pereira $^{2}$, Éder Rodrigues Peres ${ }^{5}$, Marcos Laux Leão ${ }^{6}$
}

${ }^{1}$ CNPq.

2 PPG em Zootecnia, Departamento de Plantas Forrageiras e Agrometeorologia da Universidade Federal do Rio Grande do SUI - UFRGS.

${ }^{3}$ Departamento de Plantas Forrageiras e Agrometeorologia da Universidade Federal do Rio Grande do Sul - UFRGS.

${ }^{4}$ Embrapa Pecuária Sul.

5 Graduação em Agronomia - UFRGS (Bolsista Embrapa Pecuaria Sul).

${ }^{6}$ Graduação em Agronomia - UFRGS (Bolsista no Departamento de Plantas Forrageiras e Agrometeorologia da Universidade Federal do Rio Grande do Sul).

RESUMO - Realizou-se neste estudo uma avaliação inicial em diversas linhagens de aveia-branca (Avena sativa, L.), com o intuito de verificar o desempenho agronômico e identificar os genótipos promissores para o lançamento de cultivares para produção de forragem. Os experimentos foram conduzidos em duas regiões fisiográficas do estado do Rio Grande do Sul, Depressão Central e Campanha Gaúcha, nos anos de 2008 e 2009. Foram implementados em blocos casualizados com quatro repetições. Cada parcela foi constituída por uma linha de $2 \mathrm{~m}$ de comprimento, espaçadas a $40 \mathrm{~cm}$ entre si, considerando parcela útil o metro linear central, cortadas a uma altura de $10 \mathrm{~cm}$. Foram avaliadas 21 linhagens de aveia-branca mais a testemunha (IPR126). No primeiro ano, também foram avaliadas duas linhagens de triticale, as quais apresentaram baixo potencial forrageiro e foram excluídas dos experimentos no segundo ano. Na avaliação do potencial produtivo das linhagens de aveia-branca, não houve diferenças ocasionadas pela interação dos fatores local, ano e linhagem. No primeiro ano, os valores médios de produção na Depressão Central e Campanha Gaúcha foram de 82,3 e 76,3 g por metro linear de matéria seca total, respectivamente. Na avaliação do segundo ano, as médias de produção para esta espécie na Depressão Central e na Campanha Gaúcha foram, respectivamente, 80,0 e 119,8 g m de matéria seca total. As linhagens de aveia-branca, em sua maioria, apresentam bons resultados e são promissoras para o programa de melhoramento genético dessa espécie.

Palavras-chave: Avena sativa L., forragem, melhoramento genético

\section{Agronomic evaluation of white oats strains in two geographical regions of the state of Rio Grande do Sul}

\begin{abstract}
The objective of this study was to proceed with an initial evaluation of various strains of white oats (Avena sativa, L.), with the objective of characterizing the genetic diversity and the agronomic performance, identifying the promising genotypes for the release of cultivars, with the purpose of forage production. The experiments were conducted in two geographical regions of the State of Rio Grande do Sul, Depressão Central and in the Campanha Gaúcha, Brazil, in the years 2008 and 2009, in a randomized block design with four replications. Each plot consisted of a 2-m line, with lines spaced at $40 \mathrm{~cm}$. The central linear meter was considered as useful plot, cut to a height of $10 \mathrm{~cm}$. Twenty-one oat lines were evaluated, plus the control (IPR126). In the first year, two strains of triticale were also studied, and had a low potential for forage and were excluded from the experiments in the second year. The productive potential of oat strains did not differ for the interaction of location, year or lineage, with the first year of average production in the Depressão Central and Campanha Gaúcha, of, 823 and 76.3 grams per meter of total dry matter (TDM), respectively. At the second year evaluation, the means of production for this species in the Depressão Central and Campanha Gaúcha were 80.0 and $119.8 \mathrm{~g} \mathrm{~m}^{-1}$ TDM. Most strains of oats present good results and are promising for the breeding program of this species.
\end{abstract}

Key Words: forage, plant breeding, white oat 


\section{Introdução}

No Rio Grande do Sul, as pastagens naturais têm grande relevância na produção animal, devido à grande diversidade de espécies, muitas delas com alto potencial forrageiro. Todavia, essas pastagens naturais são compostas predominantemente por espécies de ciclo estival, levando a uma deficiência na produção de forragem durante o período frio do ano.

O uso de pastagens cultivadas de estação fria é uma alternativa para reduzir o período crítico de produção de forragem, e as espécies mais utilizadas para este período são a aveia-preta (Avena strigosa S.) e o azevém (Lolium multiflorum Lam.), de forma isolada ou consorciada, uma vez que essas espécies apresentam alta produção de forragem e qualidade (Roso et al., 1999).

A utilização de aveia-branca, por outro lado, deve-se à sua produção e às diversas formas como esta cultura pode ser empregada, como pastejo direto, produção de grãos e cobertura de solo, e pode ser oferecida diretamente no cocho, como massa verde, silagem ou feno. Já a aveia-preta é a mais utilizada para forragem, especialmente por apresentar maior rusticidade em comparação à aveia-branca.

Embora as espécies de aveia sejam muito utilizadas na Região Sul do Brasil, há dificuldades na sua implantação, devido ao pequeno número de cultivares lançados para o pastejo direto. A aveia-branca tem maior concentração de cultivares para produção de grãos e poucos para produção de forragem, portanto, o melhoramento genético dessa espécie torna-se necessário para o lançamento de cultivares mais produtivos e adaptados ao pastejo direto.

Objetivou-se com este trabalho realizar a avaliação agronômica de linhagens de aveia-branca em dois locais com características distintas, visando à seleção de materiais que possam ser utilizados como genitores em um programa de melhoramento genético que vise o lançamento de cultivares com aptidão ao pastejo nestas regiões.

\section{Material e Métodos}

Foram instalados dois experimentos nos anos de 2008 e 2009 em dois locais pertencentes a regiões fisiográficas distintas do Estado do Rio Grande do Sul. Um dos locais foi a Estação Experimental Agronômica da Faculdade de Agronomia da UFRGS em Eldorado do Sul EEA.

O clima é o subtropical úmido, da classe $\mathrm{Cfa}$, segundo classificação de Köppen, com verão quente, tendo como temperatura média anual de $19,4^{\circ} \mathrm{C}$. A média das temperaturas máximas do mês de fevereiro e a média das temperaturas mínimas no mês de junho são, respectivamente, 24,9 e
$13,9{ }^{\circ} \mathrm{C}$. A precipitação média anual é de $1.400 \mathrm{~mm}$, e os meses de junho a agosto são os mais chuvosos, enquanto normalmente ocorre deficiência hídrica nos meses de novembro a março. O solo da área experimental, pertencente à Unidade de Mapeamento São Gerônimo, é classificado como Argissolo Vermelho Distrófico Típico - Pvd de textura argilosa e relevo ondulado e tem como substrato o granito (Streck et al., 2002). Neste ambiente, foram instalados dois dos quatro experimentos: um em 2008 e outro em 2009.

O outro local onde foram instalados os outros dois experimentos foi EMBRAPA Pecuária Sul em Bagé CPPSUL. O clima é o mesotérmico subtropical, da classe Cfa, segundo classificação de Köppen, com invernos relativamente frios e geadas frequentes. A temperatura média anual é de $17,6^{\circ} \mathrm{C}$ e as médias do mês mais frio (julho) e do mês mais quente (janeiro) são, respectivamente, 12 e $24^{\circ} \mathrm{C}$. A precipitação média anual é de 1.350 mm e o período mais chuvoso é o inverno (DNMET, 1992). O solo da área é denominado Luvissolo Hipocrômico Órtico Típico, de textura argilosa, relevo ondulado e substrato de granito (EMBRAPA, 1999). Neste ambiente, os experimentos também foram feitos em dois anos: um em 2008 e outro em 2009.

As áreas dos experimentos foram preparadas 15 dias antes da data do plantio: foram dessecadas com herbicida total, aradas e gradeadas. Após análise de solo, realizadas de acordo as recomendações da Rede Oficial de Laboratórios de Análise de Solos (SBCS, 2004), de cada área, foram aplicados corretivos e fertilizantes para gramíneas de estação fria. Para correção dos níveis de fósforo e potássio, foi realizada uma única aplicação de adubação de base alguns dias após o plantio, enquanto a aplicação de nitrogênio foi fracionada, sendo $20 \mathrm{~kg} / \mathrm{ha}$ aplicados juntamente com os demais elementos e o restante da quantidade recomendada foi disponibilizado às plantas no início do perfilhamento e após cada corte, totalizando $150 \mathrm{~kg}$ de $\mathrm{N}$.

As linhagens utilizadas nos experimentos foram fornecidas pelo Programa de Melhoramento Genético de Aveia do Departamento de Plantas de Lavoura, da Faculdade de Agronomia da UFRGS.

No ano de 2008 os experimentos foram implantados no dia 19 de maio em ambos os locais. Na EEA foram semeadas 21 linhagens de aveia-branca (ICFJ99426, UFRGS017164-1, UFRGS017164-3, UFRGS01B6194-3-3,UFRGS01B6201-5-3, UFRGS01B6201-5-4, UFRGS047089-2, UFRGS07Q9001-1, UFRGS07Q9004-3, UFRGS07Q9005-1, UFRGS07Q9015-2, UFRGS07Q9016-1, UFRGS07Q9022-3, UFRGS12, UFRGS36095, UFRGS930551-6, UFRGS940060, UFRGS953133, UFRGS960797, UFRGS9912002-1 e UFRGS995034-2), duas linhagens de triticale (URSTC 06BT52-5 e URSTC 06BT91-3) e uma testemunha (IPR 126). 
No CPPSUL foram semeadas as mesmas linhagens, com exceção do genótipo UFRGS 07Q9005-1, devido à pouca disponibilidade de sementes. No ano de 2009, a semeadura ocorreu no dia 29 de maio, em ambos os locais, com a utilização das mesmas linhagens e testemunha do ano anterior, com exceção das duas linhagens de triticale, que foram excluídas, devido ao seu baixo desempenho no primeiro. A densidade de semeadura utilizada foi de 6,0 g de sementes puras e viáveis por $\mathrm{m}^{2}$, conforme recomendado pelo Ministério da Agricultura, Pecuária e Abastecimento (MAPA).

O delineamento adotado foi o de blocos casualizados com quatro repetições para todos os locais e anos. Cada parcela foi constituída de uma linha de $2 \mathrm{~m}$ de comprimento, considerando área útil o metro linear central cortado a uma altura de $10 \mathrm{~cm}$ do solo, na qual as plantas atingiam em torno de $30 \mathrm{~cm}$ de altura. As parcelas eram espaçadas a $40 \mathrm{~cm}$ entre si. Após cada corte, o material amostrado foi separado para avaliação da produção de matéria seca (MS) de lâminas foliares e colmos mais bainhas e inflorescências. As amostras foram acondicionadas em estufa de circulação de ar forçado a $65{ }^{\circ} \mathrm{C}$, onde foram mantidas até peso constante para estimativa da produção de MS de forragem de cada componente em g.m ${ }^{-1}$ linear. Foram avaliadas as seguintes variáveis nos quatro experimentos: matéria seca total (MST) e matéria seca de lâminas foliares (MSF).
Foram realizadas análises estatísticas, análises individuais por ano e local, em esquema de parcelas subdivididas no tempo, com o fator linhagem alocado nas parcelas principais e o fator corte (tempo) nas subparcelas. Com as produções acumuladas dos cortes, foi realizada a análise conjunta no esquema fatorial, adotando linhagens, anos e locais como fatores. Em todas as análises, sempre quando significativas para o teste $\mathrm{F}$, efetuou-se a comparação entre médias de linhagens pelo teste de agrupamento Scott-Knott a 5\% de probabilidade, por meio do programa GENES (Cruz, 2001), e entre médias de ano e local pelo teste de Tukey a 5\% de significância por meio do pacote estatístico SAS (Statistical Analysis System, versão 8.02).

\section{Resultados e Discussão}

A avaliação do primeiro ano na EEA foi realizada no período ocorreu de maio a setembro de 2008, por meio de quatro cortes. No primeiro corte, não houve produção de colmos, pois as plantas estavam no início do estágio vegetativo e a produção de matéria seca total do primeiro corte foi representada pela produção de matéria seca de folhas (Tabela 1).

O resultado da análise de variância apresentou interação significativa entre linhagens e cortes $(P<0,05)$

Tabela 1 - Produção de matéria seca total das linhagens de aveia-branca e triticale analisadas em Eldorado do Sul, Rio Grande do Sul, 2008

\begin{tabular}{|c|c|c|c|c|c|}
\hline \multirow[t]{2}{*}{ Linhagem } & \multicolumn{4}{|c|}{ Produção de matéria seca total, $\mathrm{g} \mathrm{m}^{-1}$} & \multirow[b]{2}{*}{ Total } \\
\hline & Corte 1 (17/07) & Corte $2(07 / 08)$ & Corte $3(27 / 08)$ & Corte $4(24 / 09)$ & \\
\hline UFRGS 07Q9004-3 & $10,8 \mathrm{Ba}$ & $27,7 \mathrm{Aa}$ & $31,9 \mathrm{Aa}$ & $24,6 \mathrm{ABa}$ & 94,9 \\
\hline UFRGS 36095 & $16,8 \mathrm{Aa}$ & $30,6 \mathrm{Aa}$ & $22,4 \mathrm{Ab}$ & $24,5 \mathrm{Aa}$ & 94,3 \\
\hline UFRGS 07Q9016-1 & $13,8 \mathrm{Ba}$ & $28,5 \mathrm{Aa}$ & $31,5 \mathrm{Aa}$ & $19,6 \mathrm{ABa}$ & 93,4 \\
\hline UFRGS $017164-1$ & $8,4 \mathrm{Bb}$ & $28,3 \mathrm{Aa}$ & $29,4 \mathrm{Aa}$ & $26,1 \mathrm{Aa}$ & 92,3 \\
\hline IPR 126 & $9,6 \mathrm{Ba}$ & $29,0 \mathrm{Aa}$ & $25,7 \mathrm{Aa}$ & $27,7 \mathrm{Aa}$ & 92,1 \\
\hline UFRGS $017164-3$ & $9,7 \mathrm{Ba}$ & $23,1 \mathrm{ABa}$ & $34,1 \mathrm{Aa}$ & $21,3 \mathrm{ABa}$ & 88,2 \\
\hline UFRGS $01 B 6194-3-3$ & $11,3 \mathrm{Aa}$ & $25,2 \mathrm{Aa}$ & $21,7 \mathrm{Ab}$ & $29,5 \mathrm{Aa}$ & 87,6 \\
\hline UFRGS 9912002-1 & $14,1 \mathrm{Aa}$ & $32,0 \mathrm{Aa}$ & $16,6 \mathrm{Ab}$ & $24,2 \mathrm{Aa}$ & 87,0 \\
\hline UFRGS 07Q9005-1 & $13,8 \mathrm{Aa}$ & $25,3 \mathrm{Aa}$ & $26,0 \mathrm{Aa}$ & $20,6 \mathrm{Aa}$ & 85,8 \\
\hline UFRGS $047089-2$ & $5,8 \mathrm{Ab}$ & $19,8 \mathrm{Ab}$ & 30,9Аа & 29,1Аа & 85,6 \\
\hline UFRGS 07Q9015-2 & $13,2 \mathrm{Ba}$ & $22,9 \mathrm{Aa}$ & $28,3 \mathrm{Aa}$ & $20,6 \mathrm{ABa}$ & 85,0 \\
\hline UFRGS 930551-6 & $6,9 \mathrm{Bb}$ & $21,7 \mathrm{ABb}$ & $28,6 \mathrm{Aa}$ & $26,8 \mathrm{Aa}$ & 84,0 \\
\hline ICFT 99426 & $10,0 \mathrm{Ba}$ & $24,6 \mathrm{ABa}$ & $32,5 \mathrm{Aa}$ & $16,0 \mathrm{ABa}$ & 83,1 \\
\hline UFRGS 07Q9001-1 & $13,5 \mathrm{Aa}$ & $23,2 \mathrm{Aa}$ & $26,6 \mathrm{Aa}$ & $18,0 \mathrm{Aa}$ & 81,3 \\
\hline UFRGS 01B6201-5-4 & $9,9 \mathrm{Aa}$ & $26,5 \mathrm{Aa}$ & $23,0 \mathrm{Ab}$ & $19,6 \mathrm{Aa}$ & 79,0 \\
\hline UFRGS 07Q9022-3 & $16,4 \mathrm{Aa}$ & $24,1 \mathrm{Aa}$ & $22,3 \mathrm{Ab}$ & $15,3 \mathrm{Aa}$ & 78,1 \\
\hline UFRGS 12 & $5,7 \mathrm{Cb}$ & $19,2 \mathrm{Bb}$ & $30,7 \mathrm{Aa}$ & $22,1 \mathrm{ABa}$ & 77,7 \\
\hline UFRGS 953133 & $5,6 \mathrm{Ab}$ & $18,9 \mathrm{Ab}$ & $25,6 \mathrm{Aa}$ & $25,4 \mathrm{Aa}$ & 75,5 \\
\hline UFRGS 01B6201-5-3 & $12,4 \mathrm{Aa}$ & $26,0 \mathrm{Aa}$ & $18,7 \mathrm{Ab}$ & $18,1 \mathrm{Aa}$ & 75,3 \\
\hline UFRGS 960797 & $6,7 \mathrm{Bb}$ & $20,7 \mathrm{ABb}$ & $29,5 \mathrm{Aa}$ & $15,6 \mathrm{Ba}$ & 72,6 \\
\hline UFRGS 940060 & $3,4 \mathrm{Cb}$ & $16,6 \mathrm{Bb}$ & $24,7 \mathrm{Aa}$ & $14,8 \mathrm{Ba}$ & 59,5 \\
\hline UFRGS 995034-2 & $8,6 \mathrm{Ab}$ & $17,4 \mathrm{Ab}$ & $18,3 \mathrm{Ab}$ & $15,2 \mathrm{Aa}$ & 59,5 \\
\hline URSTC 06BT91-3 & $1,9 \mathrm{Bb}$ & $12,0 \mathrm{ABC}$ & $16,1 \mathrm{Ab}$ & $6,8 \mathrm{ABb}$ & 36,7 \\
\hline URSTC $06 \mathrm{BT} 52-5$ & $2,9 \mathrm{Bb}$ & $11,3 \mathrm{Ac}$ & $12,5 \mathrm{Ab}$ & $6,2 \mathrm{ABb}$ & 33,0 \\
\hline Média & 9,6 & 23,1 & 25,3 & 20,3 & 78,4 \\
\hline
\end{tabular}

Médias seguidas por letras maiúsculas distintas na linha diferem $(\mathrm{P}<0,05)$ entre si pelo teste Tukey.

Médias seguidas por letras minúsculas distintas na coluna linha diferem $(\mathrm{P}<0,05)$ entre si pelo teste Scott-Knot. 
para todas as variáveis analisadas. Observando o desempenho nos cortes para produção de MS total (Tabela 1), verificou-se diferença estatística entre as linhagens formando duas classes nos cortes 1,3 e 4 e três classes no corte 2. A produção de matéria seca total da classe superior em g por metro linear ( $\left.\mathrm{g} \mathrm{m}^{-1}\right)$ variou de 9,6 a 16,8; 22,9 a 32; 24,7 a 34,1; e 14 a 29,5 g nos cortes 1, 2, 3 e 4, respectivamente. A produção da classe inferior variou de 1,9 a 8,6; 11,3 a 12; 12,5 a 23; e de 6,2 a 6,8 g nos cortes 1, 2, 3 e 4, respectivamente.

As linhagens de aveia-branca UFRGS 07Q9001-1, UFRGS 07Q9004-3, UFRGS 07Q9005-1, UFRGS 07Q9015-2, UFRGS 07Q9016-1, UFRGS 017164-3, ICFT 99426 e a testemunha IPR 126 mantiveram-se na classe superior em todos os quatro cortes, enquanto as linhagens de triticale URSTC 06BT52-5 e URSTC 06BT91-3 mantiveram-se na classe inferior nos quatro cortes.

Das 24 linhagens, 11 não se diferenciaram $(\mathrm{P}>0,05)$ entre os cortes, mantendo produção estável desde o início do ciclo, diferente de outras, que apresentaram desenvolvimento inicial mais lento. Dessas 11 linhagens, a UFRGS 07Q9001-1 ea UFRGS 07Q9005-1, além de produção estável, mantiveram-se na classe superior em todos os cortes, porém a soma suas produções de matéria seca total dos quatro cortes foi inferior à da testemunha e de outras linhagens, por exemplo, a UFRGS 017164-1.
Observando a produção de matéria seca de lâminas foliares (Tabela 2), verificou-se diferença estatística entre as linhagens formando o mesmo número de classes que para matéria seca total, ou seja, duas classes nos cortes 1 , 3 e 4 e três no corte 2 . A produção de matéria seca foliar da classe superior, em m $^{-1}$, variou de 9,6 a 16,8; 18,8 a 28,2; 17 a 26,4; e 7,5 a 20,2 g nos cortes 1, 2, 3 e 4, respectivamente, e da classe inferior, de 1,9 a 8,6; 9 a 9,5; 5,6 a 15,1; e 1,6 a 2 g nos cortes 1, 2, 3 e 4, respectivamente.

As linhagens de aveia-branca que tiveram melhores produções de matéria seca foliar em todos os quatro cortes apresentaram também melhores produções de matéria seca total nos quatro cortes. Isso comprova bom estabelecimento inicial e produção superior à das demais linhagens. A maior a produção de folhas em relação a colmos dessas linhagens indica melhor qualidade de forragem, fator importante para qualquer cultura forrageira.

A produção de matéria seca de lâminas foliares das linhagens de triticale URSTC 06BT52-5 e URSTC 06BT91-3 também foi inferior à das linhagens de aveia-branca nos quatro cortes, apresentando, portanto, baixo potencial forrageiro. As linhagens ICFT 99426, UFRGS 017164-3, UFRGS 07Q9001-1, UFRGS 07Q9004-3, UFRGS 07Q9005-1, UFRGS 07Q9015-2, UFRGS 07Q9016-1, UFRGS 047089-2, UFRGS 12,UFRGS 930551-6, UFRGS953133,UFRGS 960797

Tabela 2 - Produção de matéria seca foliar de linhagens de aveia-branca e triticale analisadas em Eldorado do Sul, Rio Grande do Sul, 2008

\begin{tabular}{|c|c|c|c|c|c|}
\hline \multirow[t]{2}{*}{ Linhagem } & \multicolumn{4}{|c|}{ Produção de matéria seca foliar, $\mathrm{g} \mathrm{m}^{-1}$} & \multirow[b]{2}{*}{ Total } \\
\hline & Corte $1(17 / 07)$ & Corte $2(07 / 08)$ & Corte $3(27 / 08)$ & Corte $4(24 / 09)$ & \\
\hline IPR 126 & $9,6 \mathrm{Ca}$ & $28,2 \mathrm{Aa}$ & $22,9 \mathrm{Ba}$ & $20,2 \mathrm{Ba}$ & 80,9 \\
\hline UFRGS 07Q9016-1 & $13,8 \mathrm{Ba}$ & $27,2 \mathrm{Aa}$ & $22,2 \mathrm{ABa}$ & $11,1 \mathrm{Ba}$ & 74,3 \\
\hline UFRGS 07Q9004-3 & $10,8 \mathrm{Ca}$ & $26,9 \mathrm{Aa}$ & $23,7 \mathrm{ABa}$ & $12,3 \mathrm{BCa}$ & 73,7 \\
\hline UFRGS $047089-2$ & $5,8 \mathrm{Bb}$ & $19,6 \mathrm{ABa}$ & $26,4 \mathrm{Aa}$ & $17,0 \mathrm{ABa}$ & 68,9 \\
\hline UFRGS 07Q9015-2 & $13,2 \mathrm{Ba}$ & $21,7 \mathrm{Aa}$ & $21,3 \mathrm{Aa}$ & $12,3 \mathrm{Ba}$ & 68,5 \\
\hline UFRGS 07Q9005-1 & 13,8Аa & $24,3 \mathrm{Aa}$ & $19,8 \mathrm{Aa}$ & $10,2 \mathrm{Aa}$ & 68,2 \\
\hline UFRGS 930551-6 & $6,9 \mathrm{Ab}$ & $20,8 \mathrm{Aa}$ & $23,6 \mathrm{Aa}$ & $16,0 \mathrm{Aa}$ & 67,4 \\
\hline UFRGS 01B6194-3-3 & $11,3 \mathrm{Aa}$ & $23,0 \mathrm{Aa}$ & $15,1 \mathrm{Ab}$ & $16,1 \mathrm{Aa}$ & 65,6 \\
\hline UFRGS $017164-1$ & $8,4 \mathrm{Bb}$ & $26,4 \mathrm{Aa}$ & $18,0 \mathrm{ABa}$ & $12,0 \mathrm{ABa}$ & 64,8 \\
\hline UFRGS $017164-3$ & 9,7Аa & $22,2 \mathrm{Aa}$ & $22,1 \mathrm{Aa}$ & $10,7 \mathrm{Aa}$ & 64,7 \\
\hline UFRGS 07Q9022-3 & $16,4 \mathrm{Aa}$ & $22,3 \mathrm{Aa}$ & $15,1 \mathrm{Ab}$ & $10,9 \mathrm{Aa}$ & 64,7 \\
\hline ICFT 99426 & 10,0Аа & $22,9 \mathrm{Aa}$ & $20,5 \mathrm{Aa}$ & $10,4 \mathrm{Aa}$ & 63,8 \\
\hline UFRGS 07Q9001-1 & $13,5 \mathrm{ABa}$ & $22,1 \mathrm{Aa}$ & $18,7 \mathrm{ABa}$ & $7,8 \mathrm{Ba}$ & 62,0 \\
\hline UFRGS 9912002-1 & 14,1Аa & $22,3 \mathrm{Aa}$ & $12,3 \mathrm{Ab}$ & $12,3 \mathrm{Aa}$ & 61,0 \\
\hline UFRGS 12 & $5,7 \mathrm{Bb}$ & 18,9 Аа & $21,4 \mathrm{Aa}$ & $14,1 \mathrm{ABa}$ & 60,1 \\
\hline UFRGS 36095 & $16,8 \mathrm{Aa}$ & $21,9 \mathrm{Aa}$ & $10,9 \mathrm{Ab}$ & $10,2 \mathrm{Aa}$ & 59,9 \\
\hline UFRGS 01B6201-5-4 & $9,9 \mathrm{Ba}$ & $22,3 \mathrm{Aa}$ & $14,0 \mathrm{Bb}$ & $11,9 \mathrm{Ba}$ & 58,0 \\
\hline UFRGS 960797 & $6,7 \mathrm{Bb}$ & $20,0 \mathrm{Aa}$ & $20,7 \mathrm{Aa}$ & $8,5 \mathrm{Ba}$ & 55,8 \\
\hline UFRGS 01B6201-5-3 & $12,4 \mathrm{ABa}$ & $20,2 \mathrm{Aa}$ & $11,9 \mathrm{Bb}$ & $10,1 \mathrm{Ba}$ & 54,6 \\
\hline UFRGS 953133 & $5,6 \mathrm{Bb}$ & $18,8 \mathrm{Aa}$ & $20,4 \mathrm{Aa}$ & $8,1 \mathrm{Ba}$ & 52,8 \\
\hline UFRGS 995034-2 & $8,6 \mathrm{Ab}$ & $14,9 \mathrm{Ab}$ & $12,1 \mathrm{Ab}$ & $9,5 \mathrm{Aa}$ & 45,1 \\
\hline UFRGS 940060 & $3,4 \mathrm{Cb}$ & $16,3 \mathrm{Ab}$ & $17,0 \mathrm{Aa}$ & $7,5 \mathrm{Ba}$ & 44,2 \\
\hline URSTC 06BT52-5 & $2,9 \mathrm{BCb}$ & $9,0 \mathrm{Ac}$ & $5,6 \mathrm{ABb}$ & $2,0 \mathrm{Cb}$ & 19,6 \\
\hline URSTC 06BT91-3 & $1,9 \mathrm{Bb}$ & $9,5 \mathrm{Ac}$ & $6,5 \mathrm{Ab}$ & $1,6 \mathrm{Bb}$ & 19,5 \\
\hline Média & 9,6 & 20,9 & 17,6 & 11,0 & 59,1 \\
\hline
\end{tabular}

Médias seguidas por letras maiúsculas distintas na linha diferem $(\mathrm{P}<0,05)$ entre si pelo teste Tukey.

Médias seguidas por letras minúsculas distintas na coluna linha diferem $(P<0,05)$ entre si pelo teste Scott-Knot. 
e a testemunha (IPR126) tiveram os mesmos padrões de classes de matéria seca total e matéria seca de lâminas foliares em cada um dos cortes.

As linhagens ICFT 99426, UFRGS 017164-3, UFRGS 07Q9001-1, UFRGS 07Q9004-3, UFRGS 07Q9005-1, UFRGS 07Q9015-2, UFRGS 07Q9016-1 e a testemunha mantiveram-se na classe superior em todos os cortes, tanto para matéria seca total quanto para matéria seca de lâminas foliares, apresentando alto potencial forrageiro. De todas as linhagens, nove mantiveram produção de matéria seca de lâminas foliares estável desde o início e não se diferenciaram ( $\mathrm{P}>0,05)$ entre os cortes. Dessas, a linhagem UFRGS 07Q9005-1 foi a única que se manteve na classe superior, com produção estável, em todos os cortes, tanto de MS total quanto de MS de lâminas foliares, portanto, com alta qualidade de forragem desde o início do ciclo e elevada produção. Contudo, somando as produções de MS total e MS de lâminas foliares nos quatro cortes, esta linhagem apresentou produção inferior à de outras linhagens e à da testemunha, mas não diferiu estatisticamente $(\mathrm{P}>0,05)$. As produções de matéria seca total e matéria seca de lâminas foliares foram maiores nos cortes 2 e 3, tendo a produção de MSF/MST decrescente do primeiro ao último corte, o que já era esperado, devido à maior produção de colmos e inflorescências no final do ciclo.

A avaliação do segundo ano na Estação Experimental Agronômica (EEA) foi realizada no período de maio a outubro de 2009, por meio de apenas três cortes, em razão da época de semeadura e das condições meteorológicas ocorridas. O resultado da análise de variância comprovou interação significativa entre linhagens e cortes $(\mathrm{P}<0,05)$ para todas as variáveis analisadas.

Observando o desempenho da produção de MS total nos cortes (Tabela 3), verificou-se diferença estatística entre as linhagens formando duas classes em cada corte. As linhagens UFRGS 07Q9004-3, UFRGS 07Q9022-3, UFRGS 07Q9015-2 e UFRGS 995034-2 foram as únicas a se manterem na classe superior em todos os cortes. Além disso, demonstra o alto potencial da linhagem UFRGS 07Q9004-3, cuja produção de matéria seca total também foi melhor no ano anterior.

As linhagens UFRGS 07Q9004-3, UFRGS 07Q9015-2, UFRGS 995034-2, UFRGS 07Q9001-1, UFRGS 36095, UFRGS 9912002-1 e a UFRGS 953133 apresentaram produções estáveis, não diferindo do primeiro ao último corte. Dessas, as linhagens UFRGS 07Q9004-3, UFRGS 07Q9015-2 e a UFRGS 995034-2, além de produções de MS totais estáveis, mantiveram-se na classe superior em todos os cortes, e isso indica que, além do seu alto potencial, também possuem produção de MS total bem distribuída ao longo da estação de crescimento. Com isso, pode-se afirmar que são materiais de rápido estabelecimento, pois apresentaram melhores produções no primeiro corte e um longo ciclo de produção, pois também tiveram melhores produções no último corte.

Tabela 3 - Produção de matéria seca total das linhagens de aveia-branca analisadas em Eldorado do Sul, Rio Grande do Sul, 2009

\begin{tabular}{|c|c|c|c|c|}
\hline \multirow[t]{2}{*}{ Linhagem } & \multicolumn{3}{|c|}{ Produção de matéria seca total, $\mathrm{g} \mathrm{m}^{-1}$} & \multirow[b]{2}{*}{ Total } \\
\hline & Corte $1(25 / 08)$ & Corte $2(14 / 09)$ & Corte $3(29 / 10)$ & \\
\hline UFRGS 07Q9004-3 & $30,8 \mathrm{Aa}$ & $34,2 \mathrm{Aa}$ & $39,2 \mathrm{Aa}$ & 104,2 \\
\hline UFRGS 960797 & $15,2 \mathrm{Bb}$ & $40,9 \mathrm{Aa}$ & $46,2 \mathrm{Aa}$ & 102,3 \\
\hline IPR 126 & $17,2 \mathrm{Bb}$ & 38,0Aa & $44,5 \mathrm{Aa}$ & 99,7 \\
\hline UFRGS 07Q9015-2 & $27,5 \mathrm{Aa}$ & $37,1 \mathrm{Aa}$ & $34,7 \mathrm{Aa}$ & 99,3 \\
\hline UFRGS 07Q9005-1 & $21,5 \mathrm{Ba}$ & $29,2 \mathrm{ABb}$ & $36,8 \mathrm{Aa}$ & 87,5 \\
\hline UFRGS 36095 & $32,2 \mathrm{Aa}$ & $31,5 \mathrm{Ab}$ & $18,5 \mathrm{Ab}$ & 82,3 \\
\hline UFRGS $017164-1$ & $16,4 \mathrm{Bb}$ & $30,8 \mathrm{Ab}$ & $33,5 \mathrm{Aa}$ & 80,7 \\
\hline UFRGS 07Q9016-1 & $19,5 \mathrm{Bb}$ & $29,0 \mathrm{ABb}$ & $32,0 \mathrm{Aa}$ & 80,5 \\
\hline UFRGS 12 & $16,6 \mathrm{Bb}$ & 29,7Ab & 33,7Aa & 80,0 \\
\hline UFRGS 01B6201-5-4 & $13,6 \mathrm{Bb}$ & $30,5 \mathrm{Ab}$ & 35,8Аa & 79,9 \\
\hline UFRGS 01B6201-5-3 & $12,1 \mathrm{Bb}$ & $26,6 \mathrm{Ab}$ & $26,1 \mathrm{Ab}$ & 64,8 \\
\hline UFRGS 953133 & $12,8 \mathrm{Ab}$ & $24,9 \mathrm{Ab}$ & $26,9 \mathrm{Ab}$ & 64,7 \\
\hline UFRGS 930551-6 & $14,5 \mathrm{Bb}$ & $24,8 \mathrm{Ab}$ & $22,4 \mathrm{ABb}$ & 61,6 \\
\hline UFRGS 940060 & $4,0 \mathrm{Bb}$ & $17,7 \mathrm{Ab}$ & $13,2 \mathrm{ABb}$ & 34,9 \\
\hline Média & 18,4 & 30,0 & 31,3 & 79,6 \\
\hline
\end{tabular}

Médias seguidas por letras maiúsculas distintas na linha diferem $(\mathrm{P}<0,05)$ entre si pelo teste Tukey.

Médias seguidas por letras minúsculas distintas na coluna linha diferem $(P<0,05)$ entre si pelo teste Scott-Knot. 
A testemunha IPR 126 e a linhagem UFRGS 960797 não apresentaram produção de matéria seca estável. O primeiro corte foi o menos produtivo, comprovando comportamento mais tardio que nas demais linhagens, ou dificuldades no estabelecimento inicial. Contudo, seus desempenhos finais (soma de todos os cortes) foram superiores aos das linhagens UFRGS 07Q9015-2 e UFRGS 995034-2, devido à melhor produção nos dois últimos cortes.

A produção de MS de lâminas foliares (Tabela 4) apresentou diferença estatística entre as linhagens, formando duas classes no corte 1 e três nos cortes 2 e 3 . Nenhuma das linhagens se manteve na classe superior nos três cortes. Contudo, a testemunha IPR 126 apresentou melhor produção de MS de lâminas foliares em dois dos três cortes, diferenciando-se de outras que apresentaram melhores produções em apenas um corte, ou se mantiveram na classe inferior em todos os cortes. Novamente, a testemunha teve comportamento mais tardio e sua produção de MS de lâminas foliares foi maior nos dois últimos cortes. A linhagem UFRGS 930551-6 teve menor produção que a testemunha e produção superior às demais no último corte, demonstrando boa produção de folhas no último corte.

As linhagens UFRGS 930551-6 e UFRGS 017164-3 tiveram produção estável desde o início e não se diferenciaram $(\mathrm{P}>0,05)$ entre os cortes.

A avaliação do primeiro ano no CPPSUL ocorreu no período de maio a outubro, tendo sido realizados quatro cortes. A linhagem UFRGS 07Q9005-1 não foi avaliada em Bagé no primeiro ano devido à pequena disponibilidade de sementes. O resultado da análise de variância apresentou interação significativa entre linhagens e cortes $(\mathrm{P}<0,05)$ para todas as variáveis analisadas.

Na observação do desempenho da MS total entre os cortes (Tabela 5), verificou-se diferença estatística entre as linhagens, formando duas classes nos cortes 1 , 2 e 3 e quatro classes no corte 4. Apesar de nenhuma das linhagens ter se mantido na classe superior em todos os cortes, as linhagens de aveia-branca UFRGS 07Q9001-1 e a UFRGS 07Q9022-3 tiveram produções semelhantes entre si, mantendo-se na classe superior nos cortes 1 , 2 e 3 e na terceira classe no quarto corte.

A linhagem UFRGS 047089-2 e a testemunha (IPR 126) também ficaram na classe superior em três dos quatro cortes, mantendo-se na classe superior nos três últimos cortes e ficando na classe inferior no primeiro corte. Estes resultados indicam que estes materiais possuem potencial para a região da Campanha.

As linhagens de triticale URSTC 06BT52-5 e URSTC 06BT91-3, juntamente com a linhagem de aveia-branca UFRGS 01B6194-3-3, mantiveram-se na classe inferior em todos os cortes, e isso indica materiais inferiores, ou seja, de baixa produção de matéria seca neste local (CPPSUL) e ano (2008).

Comparando todas as linhagens, apenas as linhagens UFRGS 047089-2, UFRGS 930551-6 e a testemunha se

Tabela 4 - Produção de matéria seca de folhas das linhagens de aveia-branca analisadas em Eldorado do Sul, Rio Grande do Sul, 2009

\begin{tabular}{|c|c|c|c|c|}
\hline \multirow[t]{2}{*}{ Linhagem } & \multicolumn{3}{|c|}{ Produção de matéria seca de folhas $\left(\mathrm{g} \mathrm{m}^{-1}\right)$} & \multirow[b]{2}{*}{ Total } \\
\hline & Corte $1(25 / 08)$ & Corte $2(14 / 09)$ & Corte $3(29 / 10)$ & \\
\hline IPR 126 & $16,9 \mathrm{Bb}$ & $25,6 \mathrm{Aa}$ & $18,3 \mathrm{Ba}$ & 60,8 \\
\hline UFRGS 07Q9022-3 & $26,9 \mathrm{Aa}$ & $21,0 \mathrm{Ab}$ & $8,0 \mathrm{Bc}$ & 55,9 \\
\hline UFRGS 07Q9004-3 & $28,5 \mathrm{Aa}$ & $19,1 \mathrm{ABb}$ & $7,9 \mathrm{Bc}$ & 55,5 \\
\hline UFRGS 07Q9015-2 & $25,8 \mathrm{Aa}$ & $20,4 \mathrm{Ab}$ & $6,0 \mathrm{Bc}$ & 52,2 \\
\hline UFRGS 07Q9001-1 & $22,4 \mathrm{Aa}$ & $19,4 \mathrm{Ab}$ & $6,6 \mathrm{Bc}$ & 48,3 \\
\hline UFRGS 960797 & $14,9 \mathrm{Bb}$ & $25,9 \mathrm{Aa}$ & $6,7 \mathrm{Cc}$ & 47,5 \\
\hline UFRGS 07Q9005-1 & $20,9 \mathrm{Aa}$ & $17,4 \mathrm{Ab}$ & $8,4 \mathrm{Bc}$ & 46,8 \\
\hline UFRGS 995034-2 & $21,6 \mathrm{Aa}$ & $14,5 \mathrm{ABC}$ & $8,7 \mathrm{Bc}$ & 44,8 \\
\hline UFRGS 930551-6 & $14,1 \mathrm{Ab}$ & $18,4 \mathrm{Ab}$ & $11,7 \mathrm{Ab}$ & 44,3 \\
\hline UFRGS 07Q9016-1 & $18,9 \mathrm{Aa}$ & $18,0 \mathrm{Ab}$ & $7,2 \mathrm{Bc}$ & 44,0 \\
\hline UFRGS 12 & $16,2 \mathrm{Ab}$ & $18,5 \mathrm{Ab}$ & $8,9 \mathrm{Bc}$ & 43,7 \\
\hline UFRGS $9912002-1$ & $19,2 \mathrm{Aa}$ & $13,4 \mathrm{Bc}$ & $5,7 \mathrm{Cc}$ & 38,3 \\
\hline UFRGS 36095 & $26,5 \mathrm{Aa}$ & $8,9 \mathrm{Bc}$ & $2,0 \mathrm{Cc}$ & 37,4 \\
\hline UFRGS 01B6194-3-3 & $14,3 \mathrm{Ab}$ & $16,8 \mathrm{Ab}$ & $6,2 \mathrm{Bc}$ & 37,3 \\
\hline UFRGS $017164-1$ & $16,2 \mathrm{Ab}$ & $15,5 \mathrm{Ac}$ & $5,2 \mathrm{Bc}$ & 36,9 \\
\hline UFRGS $017164-3$ & $15,8 \mathrm{Ab}$ & $11,7 \mathrm{Ac}$ & $9,0 \mathrm{Ac}$ & 36,5 \\
\hline UFRGS $047089-2$ & $10,3 \mathrm{ABb}$ & $20,3 \mathrm{Ab}$ & $5,9 \mathrm{BC}$ & 36,5 \\
\hline ICFT 99426 & $12,3 \mathrm{ABb}$ & $17,0 \mathrm{Ab}$ & $5,9 \mathrm{Bc}$ & 35,3 \\
\hline UFRGS 953133 & $12,6 \mathrm{ABb}$ & $15,6 \mathrm{Ac}$ & $6,3 \mathrm{Bc}$ & 34,5 \\
\hline UFRGS 01B6201-5-4 & $13,2 \mathrm{Ab}$ & $14,2 \mathrm{Ac}$ & $5,8 \mathrm{Bc}$ & 33,3 \\
\hline UFRGS 01B6201-5-3 & $11,3 \mathrm{Ab}$ & $13,2 \mathrm{Ac}$ & $5,7 \mathrm{BC}$ & 30,3 \\
\hline UFRGS 940060 & $3,9 \mathrm{Bb}$ & $11,5 \mathrm{Ac}$ & $3,1 \mathrm{Bc}$ & 18,4 \\
\hline Média & 17,4 & 17,1 & 7,2 & 41,7 \\
\hline
\end{tabular}

Médias seguidas por letras maiúsculas distintas na linha diferem $(\mathrm{P}<0,05)$ entre si pelo teste Tukey.

Médias seguidas por letras minúsculas distintas na coluna linha diferem $(\mathrm{P}<0,05)$ entre si pelo teste Scott-Knot. 
mantiveram na classe superior no quarto corte. A linhagem UFRGS 047089-2 foi a única que apresentou produção de MS total semelhante à da testemunha. As produções de MS de lâminas foliares diferiram estatisticamente entre as linhagens nos cortes (Tabela 6), formando duas classes nos cortes 1,2 e 3 e quatro classes no corte 4 . O maior número de classes no corte 4 já era esperado, pois as linhagens apresentam diferenças em relação aos seus ciclos (precoces e tardias), diferenciando sua produção de MS, principalmente de colmos.

As linhagens UFRGS 07Q9022-3, UFRGS 07Q9001-1e UFRGS 07Q9016-1 mantiveram-se na classe superior nos três primeiros cortes, enquanto a UFRGS 930551-6 e a testemunha IPR126 mantiveram-se na classe superior nos três últimos cortes. As linhagens de triticale URSTC 06BT52-5 e URSTC 06BT91-3 mantiveram-se na classe inferior em todos os cortes, assim como observado para os resultados de matéria seca total.

Analisar as diferenças na produção de folhas de uma planta é fundamental para sua utilização como forrageira. A composição química e a digestibilidade podem variar muito entre as partes da planta, e na nutrição animal as folhas são a fração mais importante da planta, pois são consumidas preferencialmente, devido à sua maior qualidade em relação a outras partes da planta (Van Soest, 1982).
Na avaliação do comportamento de cada linhagem entre os cortes, observou-se que as linhagens de aveiabranca UFRGS 07Q9015-2, UFRGS 07Q9016-1, UFRGS 930551-6, UFRGS 940060 e as linhagens de triticale URSTC 06BT91-3 e URSTC 06BT52-5 apresentaram produção estável de folha desde o primeiro corte. Dessas, as linhagens UFRGS 07Q9016-1 e a UFRGS 930551-6 mantiveram-se na classe superior em três dos quatro cortes, mas apresentaram padrões de produção diferentes. A linhagem UFRGS 07Q9016-1 manteve-se na classe superior nos três primeiros cortes, enquanto a UFRGS 930551-6 nos três últimos. Apesar da produção estável de folhas, as linhagens de triticale, como referido anteriormente, sempre se mantiveram nas classes inferiores em todos os cortes, tanto para produção de MS de lâminas foliares quanto para produção de MS total.

A avaliação do segundo ano no CPPSUL foi realizada no período de maio a novembro de 2009, por meio de quatro cortes. O resultado da análise de variância apresentou interação significativa entre linhagens e cortes $(P<0,05)$ para todas as variáveis analisadas.

Houve diferenças estatísticas na produção de matéria seca total (Tabela 7) entre as linhagens apenas no primeiro corte, formando quatro classes. A linhagem UFRGS 07Q9022-3 foi a que apresentou a maior produção de MS

Tabela 5 - Produção de matéria seca total das linhagens de aveia-branca e triticale analisadas em Bagé, Rio Grande do Sul, 2008

\begin{tabular}{|c|c|c|c|c|c|}
\hline \multirow[t]{2}{*}{ Linhagem } & \multicolumn{4}{|c|}{ Produção de matéria seca total, $\mathrm{g} \mathrm{m}^{-1}$} & \multirow[b]{2}{*}{ Total } \\
\hline & Corte $1(07 / 08)$ & Corte $2(27 / 08)$ & Corte $3(26 / 09)$ & Corte $4(23 / 10)$ & \\
\hline UFRGS 07Q9022-3 & 24,8 Aa & $24,0 \mathrm{ABa}$ & 31,9Аа & $11,2 \mathrm{Bc}$ & 91,9 \\
\hline UFRGS 07Q9001-1 & $24,0 \mathrm{ABa}$ & $23,0 \mathrm{ABa}$ & 29,3Аа & $12,4 \mathrm{Bc}$ & 88,6 \\
\hline UFRGS $047089-2$ & $10,3 \mathrm{Bb}$ & $20,1 \mathrm{ABa}$ & $36,1 \mathrm{Aa}$ & $21,6 \mathrm{ABa}$ & 88,1 \\
\hline UFRGS $017164-1$ & $14,6 \mathrm{Bb}$ & $20,2 \mathrm{Ba}$ & $35,7 \mathrm{Aa}$ & $16,6 \mathrm{Bb}$ & 87,1 \\
\hline UFRGS 01B6201-5-3 & $15,1 \mathrm{Ab}$ & $24,5 \mathrm{Aa}$ & $29,5 \mathrm{Aa}$ & $10,2 \mathrm{Ac}$ & 79,4 \\
\hline UFRGS 01B6201-5-4 & $19,7 \mathrm{Aa}$ & $23,7 \mathrm{Aa}$ & $20,8 \mathrm{Ab}$ & $13,1 \mathrm{Ac}$ & 77,3 \\
\hline UFRGS 995034-2 & $13,8 \mathrm{Ab}$ & $26,1 \mathrm{Aa}$ & $25,2 \mathrm{Ab}$ & $11,7 \mathrm{Ac}$ & 76,7 \\
\hline ICFT 99426 & $16,2 \mathrm{Ab}$ & $23,6 \mathrm{Aa}$ & $25,6 \mathrm{Ab}$ & $10,9 \mathrm{Ac}$ & 76,3 \\
\hline UFRGS $017164-3$ & $12,6 \mathrm{Bb}$ & $18,0 \mathrm{Ba}$ & $28,7 \mathrm{Aa}$ & $13,9 \mathrm{Bc}$ & 73,1 \\
\hline UFRGS 930551-6 & $11,2 \mathrm{Ab}$ & $19,7 \mathrm{Aa}$ & $21,7 \mathrm{Ab}$ & $19,1 \mathrm{Aa}$ & 71,8 \\
\hline UFRGS 9912002-1 & $14,4 \mathrm{Ab}$ & $17,8 \mathrm{Aa}$ & $17,4 \mathrm{Ab}$ & $8,6 \mathrm{Ad}$ & 58,2 \\
\hline UFRGS 12 & $8,6 \mathrm{Bb}$ & $12,0 \mathrm{Bb}$ & $22,9 \mathrm{Ab}$ & $9,7 \mathrm{Bc}$ & 53,2 \\
\hline URSTC 06BT91-3 & $10,2 \mathrm{Ab}$ & $12,4 \mathrm{Ab}$ & $19,0 \mathrm{Ab}$ & $4,6 \mathrm{Ad}$ & 46,2 \\
\hline UFRGS 01B6194-3-3 & $5,9 \mathrm{Bb}$ & $11,7 \mathrm{ABb}$ & $18,8 \mathrm{Ab}$ & 7,6ABd & 44,1 \\
\hline URSTC 06BT52-5 & $2,6 \mathrm{Bb}$ & $2,8 \mathrm{Bb}$ & $13,5 \mathrm{Ab}$ & $3,9 \mathrm{Bd}$ & 22,7 \\
\hline Média & 13,6 & 19,0 & 25,7 & 12,2 & 70,6 \\
\hline
\end{tabular}

Médias seguidas por letras maiúsculas distintas na linha diferem $(\mathrm{P}<0,05)$ entre si pelo teste Tukey.

Médias seguidas por letras minúsculas distintas na coluna linha diferem $(P<0,05)$ entre si pelo teste Scott-Knot. 
Tabela 6 - Produção de matéria seca de lâminas foliares em gramas por metro linear das linhagens de aveia-branca e triticale analisadas em Bagé, Rio Grande do Sul, 2008

\begin{tabular}{|c|c|c|c|c|c|}
\hline \multirow[t]{2}{*}{ Linhagem } & \multicolumn{4}{|c|}{ Produção de matéria seca de lâminas foliares, $\mathrm{g} \mathrm{m}^{-1}$} & \multirow[b]{2}{*}{ Total } \\
\hline & Corte $1(07 / 08)$ & Corte $2(27 / 08)$ & Corte $3(26 / 09)$ & Corte $4(23 / 10)$ & \\
\hline UFRGS 07Q9022-3 & $23,7 \mathrm{Aa}$ & $22,7 \mathrm{Aa}$ & $24,5 \mathrm{Aa}$ & $6,4 \mathrm{Bc}$ & 77,3 \\
\hline IPR 126 & $10,9 \mathrm{Bb}$ & $20,8 \mathrm{ABa}$ & $31,4 \mathrm{Aa}$ & $12,8 \mathrm{Ba}$ & 75,9 \\
\hline UFRGS 07Q9001-1 & $23,8 \mathrm{Aa}$ & $20,2 \mathrm{Aa}$ & $19,6 \mathrm{Aa}$ & $5,6 \mathrm{Bc}$ & 69,3 \\
\hline UFRGS 07Q9015-2 & $24,6 \mathrm{Aa}$ & $24,4 \mathrm{Aa}$ & $14,4 \mathrm{Ab}$ & 3,9Ad & 67,2 \\
\hline UFRGS 07Q9016-1 & $16,9 \mathrm{Aa}$ & $18,5 \mathrm{Aa}$ & $22,6 \mathrm{Aa}$ & $8,7 \mathrm{Ab}$ & 66,6 \\
\hline UFRGS 047089-2 & $10,1 \mathrm{ABb}$ & $19,2 \mathrm{ABa}$ & $28,4 \mathrm{Aa}$ & $6,2 \mathrm{Bc}$ & 63,8 \\
\hline UFRGS 930551-6 & $10,9 \mathrm{Ab}$ & $17,4 \mathrm{Aa}$ & $18,3 \mathrm{Aa}$ & $12,8 \mathrm{Aa}$ & 59,5 \\
\hline UFRGS 01B6201-5-3 & $13,8 \mathrm{ABb}$ & $17,8 \mathrm{Aa}$ & $19,7 \mathrm{Aa}$ & 3,9Bd & 55,2 \\
\hline UFRGS 01B6201-5-4 & $19,0 \mathrm{Aa}$ & $18,5 \mathrm{Aa}$ & $13,2 \mathrm{ABb}$ & $3,6 \mathrm{Bd}$ & 54,4 \\
\hline ICFT 99426 & $15,7 \mathrm{Ab}$ & $18,8 \mathrm{Aa}$ & $14,8 \mathrm{ABb}$ & $4,0 \mathrm{Bd}$ & 53,3 \\
\hline UFRGS 995034-2 & $13,5 \mathrm{ABb}$ & $18,1 \mathrm{Aa}$ & $16,3 \mathrm{Ab}$ & $5,2 \mathrm{Bc}$ & 53,2 \\
\hline UFRGS 953133 & $9,2 \mathrm{BCb}$ & $16,8 \mathrm{ABa}$ & $20,6 \mathrm{Aa}$ & $5,5 \mathrm{Cc}$ & 52,0 \\
\hline UFRGS $017164-1$ & $14,2 \mathrm{Ab}$ & $18,1 \mathrm{Aa}$ & $15,9 \mathrm{Ab}$ & 3,3Bd & 51,6 \\
\hline UFRGS 07Q9004-3 & $13,4 \mathrm{Ab}$ & $16,5 \mathrm{Aa}$ & $16,1 \mathrm{Ab}$ & $5,1 \mathrm{Bc}$ & 51,1 \\
\hline UFRGS 017164-3 & $12,6 \mathrm{ABb}$ & $16,3 \mathrm{Aa}$ & $11,6 \mathrm{ABb}$ & $7,1 \mathrm{Bc}$ & 47,5 \\
\hline UFRGS 940060 & $13,3 \mathrm{Ab}$ & $11,6 \mathrm{Ab}$ & $17,9 \mathrm{Aa}$ & 4,0Ad & 46,9 \\
\hline UFRGS 9912002-1 & $14,1 \mathrm{Ab}$ & $12,7 \mathrm{Ab}$ & $13,5 \mathrm{Ab}$ & $3,4 \mathrm{Bd}$ & 43,7 \\
\hline UFRGS 36095 & $14,2 \mathrm{Ab}$ & $14,3 \mathrm{Ab}$ & $12,3 \mathrm{ABb}$ & $2,4 \mathrm{Bd}$ & 43,2 \\
\hline UFRGS 960797 & $6,4 \mathrm{Bb}$ & $11,7 \mathrm{ABb}$ & $18,9 \mathrm{Aa}$ & $4,8 \mathrm{Bc}$ & 41,8 \\
\hline UFRGS 12 & $8,5 \mathrm{ABb}$ & $11,0 \mathrm{Ab}$ & $11,8 \mathrm{Ab}$ & $3,2 \mathrm{Bd}$ & 34,5 \\
\hline UFRGS 01B6194-3-3 & $5,9 \mathrm{ABb}$ & $11,3 \mathrm{Ab}$ & $11,9 \mathrm{Ab}$ & $2,7 \mathrm{Bd}$ & 31,9 \\
\hline URSTC 06BT91-3 & 7,9Ab & 7,3Ab & $11,1 \mathrm{Ab}$ & 2,8Ad & 29,2 \\
\hline URSTC 06BT52-5 & $2,5 \mathrm{Ab}$ & 1,9Ab & 4,7Ab & $1,6 \mathrm{Ad}$ & 10,7 \\
\hline Média & 13,3 & 15,9 & 16,9 & 5,2 & 51,3 \\
\hline
\end{tabular}

Médias seguidas por letras maiúsculas distintas na linha diferem $(\mathrm{P}<0,05)$ entre si pelo teste Tukey.

Médias seguidas por letras minúsculas distintas na coluna linha diferem $(\mathrm{P}<0,05)$ entre si pelo teste Scott-Knot.

Tabela 7 - Produção de matéria seca total das linhagens de aveia-branca analisadas em Bagé, Rio Grande do Sul, 2009

\begin{tabular}{|c|c|c|c|c|c|}
\hline \multirow[t]{2}{*}{ Linhagem } & \multicolumn{4}{|c|}{ Produção de matéria seca total, $\mathrm{g} \mathrm{m}^{-1}$} & \multirow[b]{2}{*}{ Total } \\
\hline & Corte $1(24 / 08)$ & Corte $2(11 / 09)$ & Corte $3(07 / 10)$ & Corte $4(09 / 11)$ & \\
\hline IPR 126 & $18,3 \mathrm{Ac}$ & 46,3Аа & 47,9Аа & 44,3Аа & 156,8 \\
\hline UFRGS 07Q9005-1 & $27,6 \mathrm{Ab}$ & $45,2 \mathrm{Aa}$ & $31,6 \mathrm{Aa}$ & $46,8 \mathrm{Aa}$ & 151,1 \\
\hline UFRGS 07Q9022-3 & $39,8 \mathrm{ABa}$ & 51,9Аа & $19,3 \mathrm{Ba}$ & $34,9 \mathrm{ABa}$ & 145,8 \\
\hline UFRGS $\quad 07 Q 9001-1$ & $25,1 \mathrm{Ab}$ & $42,5 \mathrm{Aa}$ & $27,2 \mathrm{Aa}$ & $37,7 \mathrm{Aa}$ & 132,5 \\
\hline ICFT 99426 & $20,7 \mathrm{Ac}$ & $39,1 \mathrm{Aa}$ & $36,5 \mathrm{Aa}$ & $35,5 \mathrm{Aa}$ & 131,7 \\
\hline UFRGS $017164-3$ & $16,1 \mathrm{Cc}$ & $40,1 \mathrm{Aa}$ & $29,1 \mathrm{Ba}$ & $45,8 \mathrm{Aa}$ & 131,1 \\
\hline UFRGS 953133 & $18,9 \mathrm{Ac}$ & 39,5Аа & $31,0 \mathrm{Aa}$ & $38,5 \mathrm{Aa}$ & 127,9 \\
\hline UFRGS $047089-2$ & $9,6 \mathrm{Ad}$ & $41,5 \mathrm{Aa}$ & $37,0 \mathrm{Aa}$ & $36,8 \mathrm{Aa}$ & 124,9 \\
\hline UFRGS 07Q9016-1 & $27,7 \mathrm{Bb}$ & $45,4 \mathrm{Aa}$ & $17,9 \mathrm{Ba}$ & $28,7 \mathrm{Ba}$ & 119,8 \\
\hline UFRGS $017164-1$ & 11,9Bd & $36,5 \mathrm{Aa}$ & $26,0 \mathrm{ABa}$ & $43,3 \mathrm{Aa}$ & 117,7 \\
\hline UFRGS 12 & $18,6 \mathrm{Ac}$ & $38,4 \mathrm{Aa}$ & $24,8 \mathrm{Aa}$ & $33,2 \mathrm{Aa}$ & 115,0 \\
\hline UFRGS $995034-2$ & $20,3 \mathrm{Ac}$ & $37,5 \mathrm{Aa}$ & $25,1 \mathrm{Aa}$ & $28,7 \mathrm{Aa}$ & 111,6 \\
\hline UFRGS 01B6194-3-3 & $15,1 \mathrm{Bc}$ & $36,0 \mathrm{Aa}$ & $24,3 \mathrm{ABa}$ & $30,6 \mathrm{ABa}$ & 106,0 \\
\hline UFRGS 960797 & $9,3 \mathrm{Cd}$ & $29,8 \mathrm{ABa}$ & $39,7 \mathrm{Aa}$ & $20,7 \mathrm{BCa}$ & 99,5 \\
\hline UFRGS 930551-6 & $18,5 \mathrm{Ac}$ & $36,5 \mathrm{Aa}$ & $22,9 \mathrm{Aa}$ & $21,3 \mathrm{Aa}$ & 99,2 \\
\hline UFRGS 940060 & $5,0 \mathrm{Bd}$ & $30,2 \mathrm{Aa}$ & $29,0 \mathrm{Aa}$ & $34,7 \mathrm{Aa}$ & 99,0 \\
\hline Média & 20,1 & 40,1 & 27,6 & 34,3 & 122,1 \\
\hline
\end{tabular}

Médias seguidas por letras maiúsculas distintas na linha diferem $(\mathrm{P}<0,05)$ entre si pelo teste Tukey.

Médias seguidas por letras minúsculas distintas na coluna linha diferem $(\mathrm{P}<0,05)$ entre si pelo teste Scott-Knot. 
total no primeiro corte, diferenciando-se de todos os demais tratamentos. Nas linhagens UFRGS 07Q9004-3, UFRGS 07Q9005-1, UFRGS 07Q9001-1, UFRGS 07Q9016-1, UFRGS 07Q9015-2 e UFRGS 36095, os valores de produção de MS total do primeiro corte foram semelhantes entre si e superiores aos da testemunha (IPR 126), comprovando rápido estabelecimento dessas linhagens e indicando alta produção logo no início do ciclo produtivo. Rápido estabelecimento e boa emergência das plantas são importantes para qualquer forrageira, principalmente aquelas como o caso da aveia utilizadas como alternativas para amenizar a escassez de forragem no outono.

Comparando o desempenho de cada linhagem entre os cortes, verificou-se que a linhagem a UFRGS 07Q9022-3, apesar de possuir bom desempenho, não apresentou produção de MS total estável e foi menos produtiva no terceiro corte. As linhagens UFRGS 07Q9004-3, UFRGS 07Q9005-1, UFRGS 07Q9001-1, ICFT 99426, UFRGS 953133, UFRGS 047089-2, UFRGS 12, UFRGS 995034-2, UFRGS 9912002-1, UFRGS 930551-6 e a testemunha (IPR126) não diferiram entre os cortes $(\mathrm{P}<0,05)$, mantendo uma produção mais estável ao longo do ciclo.

Na avaliação do desempenho da produção de MS de lâminas foliares nos cortes (Tabela 8), houve diferenças estatísticas entre as linhagens apenas nos cortes 1 e 4, com a formação de quatro e duas classes, respectivamente. As diferenças nesses cortes indicam linhagens com ciclos diferentes.
A linhagem UFRGS 07Q9022-3 também se manteve na classe superior em todos os cortes para produção de matéria seca de lâminas foliares. As linhagens UFRGS 07Q9005-1, UFRGS 07Q9016-1, UFRGS 047089-2, UFRGS 930551-6e a testemunha (IPR 126) mantiveram-se na classe superior em três dos quatro cortes, diferenciando-se entre si apenas no primeiro corte, com exceção das linhagens UFRGS 07Q9005-1 e a UFRGS 07Q9016-1, cujas produções de MS de lâminas foliares foram semelhantes $(\mathrm{P}>0,05)$ no primeiro corte.

A linhagem UFRGS 07Q9022-3, além da maior produção nos quatro cortes, apresentou também produção de MS de lâminas foliares mais estável desde o primeiro corte, comprovando ter boa produção de folhas e alto potencial em todos os cortes, o que implica boa quantidade e qualidade de forragem ao longo do ciclo. As demais linhagens tiveram seu pico de produção de MS de lâminas foliares no segundo corte, com produção crescente do primeiro até o segundo corte, decrescendo no terceiro e quarto cortes, com exceção da linhagem UFRGS 36095, cuja produção reduziu do primeiro ao ultimo corte.

Sá et al. (2009a) avaliaram nove linhagens de aveia-branca, selecionadas pelo IAPAR, em Londrina, Paraná, e relataram rendimentos de matéria seca total de 2964 - 79312 kg.ha-1, com número de cortes que variou de quatro a oito conforme as linhagens. A testemunha utilizada também foi a cultivar IPR 126, a qual apresentou oito cortes juntamente com

Tabela 8 - Produção de matéria seca de folhas de linhagens de aveia-branca analisadas em Bagé, Rio Grande do Sul, 2009

\begin{tabular}{|c|c|c|c|c|c|}
\hline \multirow[t]{2}{*}{ Linhagem } & \multicolumn{4}{|c|}{ Produção de matéria seca de lâminas foliares, $\mathrm{g} \mathrm{m}^{-1}$} & \multirow[b]{2}{*}{ Total } \\
\hline & Corte $1(24 / 08)$ & Corte $2(11 / 09)$ & Corte $3(07 / 10)$ & Corte $4(09 / 11)$ & \\
\hline IPR 126 & $18,1 \mathrm{BCc}$ & 42,0Aa & $34,7 \mathrm{ABa}$ & $15,1 \mathrm{Ca}$ & 109,9 \\
\hline UFRGS 07Q9005-1 & $27,3 \mathrm{ABb}$ & $37,2 \mathrm{Aa}$ & $23,4 \mathrm{Ba}$ & $8,8 \mathrm{Ca}$ & 96,7 \\
\hline UFRGS 07Q9022-3 & $37,6 \mathrm{Aa}$ & $28,1 \mathrm{Aa}$ & $17,2 \mathrm{Aa}$ & $12,6 \mathrm{Aa}$ & 95,4 \\
\hline UFRGS 07Q9004-3 & $29,5 \mathrm{Ab}$ & $31,8 \mathrm{Aa}$ & $24,9 \mathrm{ABa}$ & $6,5 \mathrm{Bb}$ & 92,7 \\
\hline UFRGS 07Q9016-1 & $26,8 \mathrm{Ab}$ & $34,6 \mathrm{Aa}$ & $14,2 \mathrm{Ba}$ & $9,4 \mathrm{Ba}$ & 85,0 \\
\hline UFRGS 07Q9001-1 & $24,5 \mathrm{ABb}$ & 33,3Аа & $21,2 \mathrm{ABa}$ & $3,5 \mathrm{Bb}$ & 82,4 \\
\hline ICFT 99426 & $19,9 \mathrm{ABc}$ & $29,5 \mathrm{Aa}$ & $26,9 \mathrm{ABa}$ & $5,4 \mathrm{Bb}$ & 81,6 \\
\hline UFRGS $047089-2$ & $9,5 \mathrm{Bd}$ & $37,7 \mathrm{Aa}$ & $20,9 \mathrm{ABa}$ & $12,1 \mathrm{Ba}$ & 80,2 \\
\hline UFRGS 930551-6 & $17,8 \mathrm{ABc}$ & $32,3 \mathrm{Aa}$ & $17,7 \mathrm{ABa}$ & $11,6 \mathrm{Ba}$ & 79,3 \\
\hline UFRGS 07Q9015-2 & $29,0 \mathrm{Ab}$ & $31,2 \mathrm{Aa}$ & $13,1 \mathrm{Ba}$ & $5,5 \mathrm{Bb}$ & 78,8 \\
\hline UFRGS 953133 & $18,3 \mathrm{Ac}$ & $31,8 \mathrm{Aa}$ & $22,0 \mathrm{Aa}$ & $3,9 \mathrm{Bb}$ & 76,0 \\
\hline UFRGS $017164-3$ & $15,9 \mathrm{Bc}$ & $31,6 \mathrm{Aa}$ & $24,0 \mathrm{ABa}$ & $3,8 \mathrm{Cb}$ & 75,2 \\
\hline UFRGS 995034-2 & $19,2 \mathrm{ABc}$ & 30,3Аа & $17,4 \mathrm{BCa}$ & $6,1 \mathrm{Cb}$ & 73,1 \\
\hline UFRGS 12 & $17,8 \mathrm{ABc}$ & $31,7 \mathrm{Aa}$ & $17,1 \mathrm{ABa}$ & $6,2 \mathrm{Bb}$ & 72,8 \\
\hline UFRGS 01B6201-5-4 & $17,5 \mathrm{Bc}$ & $32,2 \mathrm{Aa}$ & $16,9 \mathrm{Ba}$ & $4,1 \mathrm{Cb}$ & 70,7 \\
\hline UFRGS 01B6194-3-3 & $15,0 \mathrm{BCc}$ & $30,1 \mathrm{Aa}$ & $16,3 \mathrm{Ba}$ & $4,5 \mathrm{Cb}$ & 65,9 \\
\hline UFRGS 9912002-1 & $19,4 \mathrm{ABc}$ & $24,6 \mathrm{Aa}$ & $15,0 \mathrm{Ba}$ & $5,6 \mathrm{Cb}$ & 64,7 \\
\hline UFRGS $017164-1$ & $11,9 \mathrm{Bd}$ & $29,8 \mathrm{Aa}$ & $15,0 \mathrm{Ba}$ & $7,1 \mathrm{Bb}$ & 63,8 \\
\hline UFRGS 01B6201-5-3 & $13,3 \mathrm{Bd}$ & $24,3 \mathrm{Aa}$ & $18,7 \mathrm{ABa}$ & $5,3 \mathrm{Cb}$ & 61,6 \\
\hline UFRGS 36095 & $26,0 \mathrm{Ab}$ & $22,3 \mathrm{Aa}$ & $8,3 \mathrm{Ba}$ & $1,1 \mathrm{Cb}$ & 57,7 \\
\hline UFRGS 960797 & $9,2 \mathrm{Bd}$ & $24,7 \mathrm{Aa}$ & $19,8 \mathrm{Aa}$ & $3,4 \mathrm{Bb}$ & 57,0 \\
\hline UFRGS 940060 & $5,0 \mathrm{Cd}$ & $25,0 \mathrm{Aa}$ & $16,2 \mathrm{Ba}$ & $5,2 \mathrm{Cb}$ & 51,4 \\
\hline Média & 19,5 & 30,7 & 19,1 & 6,7 & 76,0 \\
\hline
\end{tabular}

Médias seguidas por letras maiúsculas distintas na linha diferem $(\mathrm{P}<0,05)$ entre si pelo teste Tukey.

Médias seguidas por letras minúsculas distintas na coluna linha diferem $(\mathrm{P}<0,05)$ entre si pelo teste Scott-Knot. 
outras quatro linhagens, porém sua produção de MS foi inferior a essas quatro linhagens. Comparativamente, neste trabalho, em cada um dos quatro experimentos realizados, a testemunha IPR 126 e as linhagens de aveia-branca analisadas apresentaram o mesmo número de cortes.

Os resultados da análise de variância conjunta comprovaram diferenças significativas entre linhagens, locais e anos $(\mathrm{P}<0,05)$, porém, a interação entre esses três fatores não foi significativa $(\mathrm{P}>0,05)$ para as variáveis analisadas (Tabelas 9 e 10), indicando que o comportamento relativo entre as linhagens de aveia-branca não foi influenciado pelo ambiente. As linhagens UFRGS 07Q9022-3, UFRGS 07Q9004-3 e a testemunha (IPR126) destacaram-se com maiores produções de MS total e de MS de lâminas foliares, confirmando serem os materiais com maior potencial.

As linhagens de triticale não foram avaliadas na análise conjunta dos dados, pois não foram introduzidas nos experimentos em 2009. A linhagem de aveia-branca (UFRGS 07Q9005-1) também não participou da análise conjunta, pois não foi avaliada no ano de 2008 na CPPSUL, devido à baixa disponibilidade de semente.

Sá et al. (2009b), analisando genótipos de aveia-branca e aveia-preta com a finalidade de produção de forragem, em Londrina, Paraná, encontraram produções de MS que variaram de 3.156 a $7.016 \mathrm{~kg} . \mathrm{ha}^{-1}$ e relataram que a testemunha IPR 126 apresentou maior produção de MS, diferenciando-se dos demais genótipos. A análise conjunta, dos dois anos e dois locais, também comprovou produção de MS total e MS de lâminas foliares superior para a IPR 126, não diferindo $(\mathrm{P}<0,05)$ das linhagens UFRGS 07Q9022-3, UFRGS 07Q9004-3.

Para o programa de melhoramento, é interessante que haja variabilidade genética e uma das alternativas para aumentar a variabilidade é a utilização de cruzamentos. Porém, a produção e a avaliação de híbridos artificiais em aveia geram muito trabalho e demandam muito tempo, por isso, é de suma importância que as linhagens avaliadas passem por mais avaliações em outros anos e em mais locais.

Em 2009, as produções de MS total foram significativamente maiores que em 2008, enquanto a produção de MS de lâminas foliares foi melhor em 2008. Avaliando os dois locais nos anos de 2008 e 2009, a região da Campanha Gaúcha foi a que apresentou melhores desempenhos, tanto para produção de MS total quanto para produção MS de lâminas foliares. Essas diferenças entre os dois locais e os dois anos podem ter ocorrido devido a variações climáticas de cada ano e de cada lugar.

Tabela 9 - Produtividade de matéria seca total das linhagens de aveia-branca analisadas em duas regiões fisiográficas do Rio Grande do Sul, Campanha Gaúcha (Bagé) e Depressão Central (Eldorado do Sul), em dois anos (2008, 2009)

\begin{tabular}{|c|c|c|c|c|c|}
\hline \multirow{3}{*}{ Linhagem } & \multicolumn{4}{|c|}{ Produtividade de matéria seca total, $\mathrm{g} \mathrm{m}^{-1}$} & \multirow[b]{3}{*}{ Média } \\
\hline & \multicolumn{2}{|c|}{2008} & \multicolumn{2}{|c|}{2009} & \\
\hline & Eldorado Sul & Bagé & Eldorado Sul & Bagé & \\
\hline IPR 126 & 92,9 & 90,8 & 99,7 & 156,8 & $110,1 \mathrm{a}$ \\
\hline UFRGS 07Q9022-3 & 85,9 & 90,9 & 102,5 & 145,8 & $106,3 \mathrm{a}$ \\
\hline UFRGS 07Q9004-3 & 98,0 & 70,0 & 104,2 & 151,6 & $106,0 \mathrm{a}$ \\
\hline UFRGS 07Q9001-1 & 78,0 & 88,6 & 88,8 & 132,5 & $97,0 b$ \\
\hline UFRGS $017164-1$ & 93,0 & 87,1 & 80,7 & 117,7 & $94,6 b$ \\
\hline UFRGS 047089-2 & 97,0 & 88,1 & 68,5 & 124,9 & $94,6 b$ \\
\hline UFRGS 07Q9015-2 & 82,1 & 83,9 & 99,3 & 111,1 & $94,1 b$ \\
\hline UFRGS 07Q9016-1 & 92,1 & 83,2 & 80,5 & 119,8 & $93,9 b$ \\
\hline UFRGS 01B6201-5-4 & 77,4 & 77,3 & 79,9 & 131,2 & $91,5 b$ \\
\hline UFRGS $017164-3$ & 89,0 & 73,1 & 70,6 & 131,1 & $90,9 b$ \\
\hline UFRGS 36095 & 95,5 & 71,2 & 82,3 & 108,8 & $89,4 b$ \\
\hline ICFT 99426 & 83,8 & 76,3 & 65,9 & 131,7 & $89,4 b$ \\
\hline UFRGS 9912002-1 & 88,7 & 58,2 & 71,1 & 131,3 & $87,3 c$ \\
\hline UFRGS 995034-2 & 66,6 & 76,7 & 91,2 & 111,6 & $86,6 \mathrm{c}$ \\
\hline UFRGS 960797 & 79,6 & 62,0 & 102,3 & 99,5 & $85,9 c$ \\
\hline UFRGS 953133 & 69,6 & 69,4 & 64,7 & 127,9 & $82,9 c$ \\
\hline UFRGS 01B6201-5-3 & 78,3 & 79,4 & 64,8 & 106,3 & $82,2 \mathrm{c}$ \\
\hline UFRGS 12 & 78,5 & 52,3 & 80,0 & 115,0 & $81,4 c$ \\
\hline UFRGS 930551-6 & 82,3 & 71,8 & 61,6 & 99,2 & $78,7 \mathrm{c}$ \\
\hline UFRGS 01B6194-3-3 & 78,4 & 44,1 & 70,8 & 106,0 & $74,8 d$ \\
\hline UFRGS 940060 & 61,6 & 61,0 & 34,9 & 99,0 & $64,1 d$ \\
\hline Média & 82,3 & 76,3 & 80,0 & 119,8 & 89,4 \\
\hline Média ano (2 locais) & \multicolumn{2}{|c|}{$79,3 \mathrm{~B}$} & \multicolumn{2}{|c|}{$99,9 \mathrm{~A}$} & \\
\hline Média local (2 anos) & \multicolumn{2}{|c|}{ Eldorado Sul 81,1B } & \multicolumn{2}{|c|}{ Bagé 98,0A } & \\
\hline
\end{tabular}

Médias seguidas por letras maiúsculas distintas na linha diferem $(\mathrm{P}<0,05)$ entre si pelo teste Tukey.

Médias seguidas por letras minúsculas distintas na coluna linha diferem $(P<0,05)$ entre si pelo teste Scott-Knot. 
Tabela 10 - Produtividade de matéria seca de lâminas foliares das linhagens de aveia-branca analisadas em duas regiões fisiográficas do Rio Grande do Sul, Campanha Gaúcha (Bagé) e Depressão Central (Eldorado do Sul), em dois anos (2008 e 2009)

\begin{tabular}{|c|c|c|c|c|c|}
\hline \multirow{3}{*}{ Linhagem } & \multicolumn{4}{|c|}{ Produtividade de MS de lâminas foliares, $\mathrm{g} \mathrm{m}^{-1}$} & \multirow[b]{3}{*}{ Médic } \\
\hline & \multicolumn{2}{|c|}{2008} & \multicolumn{2}{|c|}{2009} & \\
\hline & Eldorado Sul & Bagé & Eldorado Sul & Bagé & \\
\hline UFRGS 07Q9022-3 & 68,3 & 76,3 & 55,9 & 95,4 & $74,0 \mathrm{a}$ \\
\hline UFRGS 07Q9004-3 & 77,0 & 51,1 & 55,5 & 92,7 & $69,1 \mathrm{a}$ \\
\hline UFRGS 07Q9016-1 & 75,5 & 68,9 & 44,0 & 85,0 & $68,3 b$ \\
\hline UFRGS $047089-2$ & 73,4 & 63,8 & 36,5 & 80,2 & $63,5 b$ \\
\hline UFRGS 930551-6 & 69,7 & 59,5 & 44,3 & 79,3 & $63,2 b$ \\
\hline ICFT 99426 & 65,0 & 53,3 & 35,3 & 81,6 & $58,8 \mathrm{c}$ \\
\hline UFRGS $017164-3$ & 65,8 & 47,5 & 36,5 & 75,2 & $56,3 c$ \\
\hline UFRGS 995034-2 & 47,4 & 53,2 & 44,8 & 73,1 & $54,6 \mathrm{c}$ \\
\hline UFRGS 953133 & 55,8 & 52,0 & 34,5 & 76,0 & $54,6 c$ \\
\hline UFRGS 960797 & 57,7 & 41,8 & 47,5 & 57,0 & $51,0 \mathrm{c}$ \\
\hline UFRGS 01B6194-3-3 & 63,0 & 31,9 & 37,3 & 65,9 & $49,5 c$ \\
\hline UFRGS 36095 & 55,3 & 43,2 & 37,4 & 57,7 & $48,4 \mathrm{c}$ \\
\hline UFRGS 12 & 21,8 & 25,9 & 43,7 & 72,8 & $41,1 \mathrm{c}$ \\
\hline UFRGS 940060 & 45,0 & 46,9 & 18,4 & 51,4 & $40,4 \mathrm{c}$ \\
\hline Média & 64,7 & 53,2 & 38,3 & 75,2 & 54,6 \\
\hline Média ano (2 locais) & \multicolumn{2}{|c|}{$58,9 \mathrm{~A}$} & \multicolumn{2}{|c|}{$56,8 \mathrm{~B}$} & \\
\hline Média local (2 anos) & \multicolumn{2}{|c|}{ Eldorado Sul 51,5B } & \multicolumn{2}{|c|}{ Bagé 64,2A } & \\
\hline
\end{tabular}

Médias seguidas por letras maiúsculas distintas na linha diferem $(\mathrm{P}<0,05)$ entre si pelo teste Tukey.

Médias seguidas por letras minúsculas distintas na coluna linha diferem $(P<0,05)$ entre si pelo teste Scott-Knot.

\section{Conclusões}

A maioria das linhagens de aveia-branca apresenta bons rendimentos, independentemente da região fisiográfica analisada. A discriminação das linhagens é maior quando feita pela produção de matéria seca total. Entre as linhagens avaliadas, as melhores são UFRGS 07Q9022-3 e UFRGS 07Q9004-3. Em Bagé, a aveia-branca apresenta maior produção de matéria seca total e de lâminas foliares.

\section{Referências}

CRUZ, C.D. Programa GENES: aplicativo computacional em genética e estatística. Viçosa, MG: UFV, 2001. 648p.

DEPARTAMENTO NACIONAL DE METEOROLOGIA - DNMET. Normais climatológicas (1961-1990). Brasília: DNMET, 1992. 84p.

EMPRESA BRASILEIRA DE PESQUISA AGROPECUÁRIA EMBRAPA. Centro Nacional de Pesquisa de Solos. Sistema brasileiro de classificação de solos. Brasília: Embrapa
Produção de Informação; Rio de Janeiro: Embrapa Solos, 1999. $412 p$.

SÁ, J.P.; OLIVEIRA, J.C.; ARAGÃO, A.A. Ensaio preliminar de aveias para forragem, em Londrina, PR, 2008. In: REUNIÃO DA COMISSÃO BRASILEIRA DE PESQUISA DE AVEIA, 29. 2009, Porto Alegre. Resultados experimentais... Porto Alegre, 2009a. p.440-441.

SÁ, J.P.; OLIVEIRA, J.C.; ARAGÃO, A.A. Ensaio nacional de aveia forrageira, em Londrina, PR, 2008. In: REUNIÃO DA COMISSÃO BRASILEIRA DE PESQUISA DE AVEIA, 29., 2009, Porto Alegre. Resultados experimentais... Porto Alegre, 2009b. p.455-456.

SOCIEDADE BRASILEIRA DE CIÊNCIA DO SOLO - SBCS. Comissão de Química e Fertilidade do Solo. Manual de adubação e calagem para os Estados do Rio Grande do Sul e Santa Catarina (Rolas). 10.ed. Porto Alegre: UFRGS, 2004. 400p.

STRECK, E.V.; KÄMPF, N.; DALMOLIN, R.S.D. et al. Solos do Rio Grande do Sul. Porto Alegre: Emater/RS, 2002. 126p.

ROSO, C.; RESTLE, J.; SOARES, A.B. et al. Produção e qualidade de forragem da mistura de gramíneas anuais de estação fria sob pastejo contínuo. Revista Brasileira de Zootecnia, v.28, n.3, p.459-467, 1999.

VAN SOEST, P.J. Nutritional ecology of the ruminant. Corvallis: O \& B Books, 1982. 374p. 